\title{
STRESS RELATED CHANGES IN IMMUNOLOGICAL AND PSYCHOLOGICAL VARIABLES INDUCED BY THE PREPARATION AND DEFENSE OF A PHD-THESIS
}

\author{
YANDA VAN ROOD*, ELS GOULMY*, ELS BLOKLAND*, \\ JOS POOL*, JON VAN ROOD* and HANS VAN HOUWELINGEN** \\ * Departments of Immunohaematology and Blood Bank \\ University Hospital Leiden, \\ and ** Department of Medical Statistics, University of Leiden, The Netherlands \\ (Received 16 July, 1992; in final form 22 March, 1994)
}

\begin{abstract}
Results are reported from a field study on 47 healthy subjects preparing and defending a PhD-thesis in the Netherlands. Measurements before, about and after thesis defense are used to quantify the temporal effects of this perceived stressor on immunological and psychological variables. Moreover, multivariate analysis of variance for repeated measurements was used to explore a potential causal relationship between changes in immune variables and changes in psychological variables. Significant temporal effects were observed for the immunological variables, percentage CD4 cells $(p=0.037)$, the proliferative response to pokeweed mitogen $(p=0.040)$, concanavalin A $10 \mu \mathrm{g} / \mathrm{ml}(p=0.010)$ and concanavalın A $40 \mu \mathrm{g} / \mathrm{ml}(p=0.005)$ and the psychological variables, average subjective distress $(p=0.002)$, highest subjective distress $(p=0.000)$ and the coping strategy depressive reaction pattern $(p=0.02)$. No evidence was obtained for a causal relation between the immunological and psychological variables.
\end{abstract}

KEY WORDS: Stressor, psycho-immunology, repeated measurements, healthy subjects, humans.

\section{INTRODUCTION}

Stress related changes in immune response have been observed both in animals and in humans (Ader, 1981; Ader, Felten and Cohen, 1991). In humans, the significant changes in immune response in relation to an exam, a stressful event, support the evidence that examination stress can alter the immune response, at least for some immunological variables (for a review and meta-analysis see van Rood et al., 1993). None of these studies were truly experimental, i.e. randomly assigned subjects to the experimental or control conditions, and only three studies used control groups (Dorian et al., 1982, Vassend and Halvorsen, 1987; Workman and La Via, 1987). In all the other studies subjects were used as their own controls.

Four studies (Jemmott et al., 1983, 1988; Vassend and Halvorsen, 1987; Mouton et al., 1989) assessed changes in psychological variables parallel to those in immunological variables. Jemmott et al. (1983) and Mouton et al. (1989) observed a significant negative relation between salivary $\operatorname{IgA}$ concentrations and perceived stressfulness. Vassend and Halvorsen (1987) observed a significant positive correlation

Address of correspondence: Yanda van Rood, PhD, currently at the Department of Psychiatry (BIP), University Hospital Leiden, P.O.Box 9600, 2300 RC Leiden, The Netherlands. 
between IgM concentrations and scores on the State-Trait Anxiety Inventory, the General Health Questionnaire, the Symptom Check List, and the Eysenck Personality Inventory. Finally, Jemmott et al. (1988) observed a significant positive correlation between social support and salivary $\operatorname{IgA}$ concentrations.

In the other studies psychological measures were used to test the hypothesis that reported distress was significantly higher during examination periods than during baseline periods, but not used to test whether changes in psychological measures were related to changes in immunological data. Instead, the statistical analysis of the data was based on the grouping of subjects according to the outcome on a psychological variable, such as loneliness, perceived stressfulness and life events, and analyzing the effect of this grouping and of time in relation to the stressful event on immunological variables by analysis of variance. Although significant main effects (grouping and time) and interaction effects (grouping by time) were observed, this statistical method does not allow for the conclusion that the association between the psychological and immunological variables is a causal one, nor that the observed changes in immune response are caused by the changes in stress.

To investigate causality in non-experimental field studies we propose to use a statistical method that is closely related to repeated measures MANOVA. In our study two groups of variables, namely psychological and immunological, were used to assess the effect of the stressor on the individual. To test the hypothesis of causality we assess the association between the psychological variables $(X)$ and immunological variables (Y), both measured several times, at three levels, namely the subject level, the time level and the change-within-subject level and base our conclusions on the consistency of the associations at the three levels.

The association between $\mathrm{X}$ and $\mathrm{Y}$ at the subject level can be determined by correlating the mean values, corrected for time-effect, of $X$ and $Y$ for each subject. The association at the time level can be assessed by correlating the mean values, over subjects, of $\mathrm{X}$ and $\mathrm{Y}$ for each time the variable was measured. However, only a significant association between $X$ and $Y$ at the change-within-subject level which is consistent with the observed association between $X$ and $Y$ at the time level indicates that there exists a causal relation between $X$ and $Y$. For, it is to be expected that the observed time-effect on $Y$ disappears when using $X$ as a covariate in the statistical analysis of variance, showing that the time-effect on $\mathrm{Y}$ is induced by the time-effect on $\mathrm{X}$. If there is no association between $\mathrm{X}$ and $\mathrm{Y}$ at the change-within-subject level, it is impossible to conclude that a time pattern for $\mathrm{Y}$ is explained by a similar pattern for X (Crowder and Hand, 1990).

In this paper we report a study on stress related changes induced by thesis preparation and defense. The aim of this study was first to investigate the effect of such a stressor on immunological and psychological variables, i.e. to test for a significant time effect. The second aim was to explore a potential causal relationship between immunological and psychological variables by an indepth statistical analysis of the association between the changes over time for both type of variables.

\section{METHOD}

This study used.a longitudinal prospective design to investigate the possibility of a truly causal relationship by assessing the association between scores of subjective 
distress and a number of immunological variables on the three levels discussed above. To increase the possibility of detection of a significant association between psychological and immunological variables, the variability in subjective distress was enhanced by planning the data collection around a stressful life event, i.e. the defense of a PhD thesis. Defense of a thesis in the Netherlands consists of an interrogation of 45 minutes by professors and members of the examination committee. Although one never fails this exam, the public defense in itself is for many students a stressful experience. Furthermore, four to eight weeks before the defense of the thesis the committee has to accept the final version and directly afterwards it has to be sent to the publisher. Since the date of defense is already set at this time, this period is generally experienced as strenuous.

\section{Subjects}

Forty-seven $\mathrm{PhD}$ students, all of whom expected to defend their thesis in May or June 1986 at the Leiden University, participated in the study. From the initial group of 59 $\mathrm{PhD}$ students who gave their informed consent, six subjects left the study after the first data-sampling, five because they experienced the venapuncture as too stressful and one person because she was diagnosed as suffering from chronic myeloid leukaemia. Subjects were asked to report on each occasion the number of alcohol containing beverages per day, the number of cigarettes (and/or cigars and pipe) smoked per day, as well as their weight. After data collection was completed, three persons were excluded because they reported an average consumption of 4 glasses of alcohol per day on all sample-points, which would lead to unreliable assessment of immunological variables (MacGregor, 1986), two subjects because they did have a chronic disease for which they used immune-modulating medication and one subject because of a change in diet resulting in substaintial loss in weight of $20 \mathrm{~kg}$, which would lead to unreliable assessment of immunological variables (Vaisman et al., 1990). The 47 remaining subjects included 41 males and 6 females whose average age was 35 years ( $s d 6.3$, range $26-58$ years).

\section{Procedure}

Simultaneously immunological and psychological data were obtained five times, between February 1986 and January 1987. It was our intention to obtain measurements 3 months before, 2 weeks before, 2 weeks after, 3 months after and 6 months after defense of the thesis. However, during data collection it appeared that the actual date of the defense of the thesis was quite often postponed. Hence, the data collected are irregularly spaced with respect to the actual date of defense. We decided to define post-hoc twelve time-periods, I to XII, in relation to the exact date of the defense of the tnesis (see Table 1 for definitions of time-periods). The $235(47 \times 5)$ observation points are irregularly placed in this $47 \times 12$ data-matrix. Table 1 gives details about the number of observations per post-hoc defined time-period. The incomplete datarnatrix was analysed by ANOVA-techniques for missing values (see section 5.4 of Fleiss, 1986). Of the 235 potential observations 20 (9\%) were missing due to the absence of the subject on one occassion, usually the last one. Twelve subjects did not defend their thesis in 1986; consequently all their data fell in time-period I and II. 
Table 1 Moment of data sampling and number of observations per post-hoc defined time-period

\begin{tabular}{lcc}
\hline Time-period & Number of weeks before or after defense of the thesis & Number of observations \\
\hline I & upto 24 weeks before & 55 \\
II & 24 to 12 weeks before & 21 \\
III & 12 to 8 weeks before & 11 \\
IV & 8 to 4 weeks before & 10 \\
V & 4 to 2 weeks before & 12 \\
VI & 2 to 0 weeks before & 21 \\
VII & 0 to 2 weeks after & 13 \\
VIII & 2 to 4 weeks after & 18 \\
IX & 4 to 12 weeks after & 16 \\
X & 12 to 16 weeks after & 15 \\
XI & 16 to 24 weeks after & 13 \\
XII & more than 24 weeks after & 10 \\
\hline
\end{tabular}

\section{Psychological data}

Subjective distress measures. Psychological data consisted of three values for subjective distress; average subjective distress, highest subjective distress and lowest subjective distress. Subjective distress was measured using a ten-point scale in which 0 represented the total absence of feelings of distress and 10 represented the highest feeling of distress one could imagine. Every subject was asked to mark with different symbols their average, highest and lowest subjective distress as experienced during the last month. Sofar, the validity of this scale has not been investigated.

Stressful life events. The Dutch questionnaire for the assessment of stressful life events in the previous year consists of 115 items reflecting 59 life events (van de Willige et al., 1985). In contrast with the other measurements this questionnaire was administered only twice, at the beginning and at the end of the study. The first observations all fell in the post-hoc periods I and II. The last observations were more spread out in the post-hoc time scale, most of these fell in the later periods, IX to XII.

Coping. A short coping list was developed by selecting those two questions which loaded highest on the original 7 factors of the "Utrechtse Coping Lijst" (UCL, Schreurs et al., 1988). Factor analysis on 14 items revealed four factors (11 items) representing different coping strategies: seeking distraction (4 items, Cronbach's $\alpha: 0.68$ ), depressive reaction pattern (3 items, Cronbach's $\alpha: 0.66$ ), active problem solving (2 items, Cronbach's $\alpha: 0.66$ ) and expression of emotions (2 items, Cronbach's $\alpha: 0.73$ ). The subjects were asked to rate on a 4-point scale the extent to which they used the four coping stategies, in general, in the last month. Rating of the test was identical to that of the complete UCL.

General Health Questionnaire. The sum-score on the General Health Questionnaire (GHQ, Dutch version 30-items) which consists of items covering psychological/ psychiatric symptoms, was used to assess the degree of psychological distress in the last month (Goldberg and Hillier, 1979).

\section{Immunological data}

Directly after the completion of the questionnaires the blood samples were collected. In order to limit diurnal variations all blood samples were collected in the morning between 9 and 12 a.m. For each subject the hour at which blood samples were collected remained constant $( \pm 1 / 2$ hour $)$ during the whole study. Forty $m$ of blood was collected 
in preservative heparin to be used for the cellular assays and $4 \mathrm{ml}$ blood defibrinated with ethylenediaminetetraacetate (EDTA) for whole blood cell count. Finally, $10 \mathrm{ml}$ blood without addition of anti-coagulant was collected for serum sampling. For all assays 47 subjects were tested, with exception of the CML for which only 21 subjects were tested, due to some technical problems.

Whole blood cell counts. Whole blood cell counts and differential cell counts were analyzed by the Coulter counter. Information was obtained on the concentration of haemoglobulin ( $\mathrm{HB} \mathrm{mmol} / \mathrm{L})$, number of erythrocytes $\left(10^{12} / \mathrm{L}\right)$ and the haematocrite volume; $\mathrm{MCV}, \mathrm{MHC}$ and $\mathrm{MCHC}$ were computed from the above information. Within the population of leucocytes the percentage of eosinophiles, basophiles, polymorphic nuclear cells, neutrophils, lymphocytes and monocytes was assessed.

Serum IgG and IgM concentrations. Serum was assayed for albumin, IgG and IgM using a Beckmann Array Protein system. All tests were performed under the manufacturers' conditions (Sternberg, 1977; Salden et al., 1988).

Isolation, freezing and thawing of peripheral blood lymphocytes. From the heparinized blood samples peripheral blood lymphocytes (PBLs) were isolated by Ficoll-Isopaque density gradient centrifugation, washed and resuspended in RPMI 1640 dimethylsulphoxide (final concentration 10\%) for cryopreservation in liquid nitrogen. The peripheral blood lymphocytes (PBLs) were kept frozen in liquid nitrogen until all blood samples were collected.

On the day of the assay, all samples of a given subject were thawed. The PBLs were used for phenotypic analyses and for the assessment of cytotoxic activities by the use of the Cell Mediated Lympholysis (CML) assay, the proliferative antigen specific response by the use of the Mixed Lymphocyte Culture (MLC) and mitogenic proliferative response by the use of the Lymphocyte Transformation Test (LTT).

Phenotypic analysis. The mononuclear cells were stained by a standard indirect immunofluorescence technique. The following monoclonal antibodies were used: anti-CD3 (OKT3; all T cells), anti-CD4 (OKT4; $\mathrm{T}$ helper/inducer cells), anti-CD8 (OKT8; T cytotoxic/suppressor cells), anti-CD16 (Leu 11b; Fc of the IgG receptor, NK cells and neutrophils), anti-TAC (TAC; IL-2 receptor), anti-OKMI (OKMI; T suppressor cells, NK cells, monocytes and granulocytes) and the control Goat anti Mouse (GAM), and assayed on a Fluorescence Activated Cell Sorter (FACS analyzer, Becton Dickinson).

Cell Mediated Lympholysis (CML). The PBLs from the different bleeding dates of one subject were used as responder cells and sensitized against three stimulator cell pools each consisting of three healthy individuals carrying different HLA antigens. Cytotoxicity was measured using the standard CML assay described previously in detail (Goulmy, 1982). Standard errors of the mean of triplicate determinations were less than 5\%. The CML test was carried out at three effector to target cell ratios; $40: 1$, $20: 1$ and $10: 1$. The results of the titration were used to evaluate the test and the results of the 40:1 ratio were used for further statistical analysis.

Mixed Lymphocyte Culture (MLC). For the MLC culture the same three pooled cells as in the CML were used as stimulator cells to generate proliferative responses which were measured after 5 days of culturing. The MLC tests were performed as described previously (Hartzmann et al., 1971). The experimental value is computed as the median of the results of the triplicate cultures, expressed in counts per minute. In order to reduce the impact of the extreme high and low values the $\log _{10}$ of the counts per minute was used for further analysis. 
Lymphocyte Transformation Test (LTT). PBLs were incubated in tissue culture medium for 2 days with addition of the mitogens: phytohaemagglutinin (PHA), pokeweed (PWM) and concanavalin A (Con A). To the $100 \mu \mathrm{l}$ cell suspension $100 \mu \mathrm{l}$ of the following mitogens were added: PHA (HA-16 Wellcome, $2 \mathrm{mg} / 5 \mathrm{ml}$ ) from an $4 \mu \mathrm{g} / \mathrm{ml}$ dilution; PWM (Barker and Farnes, cat. no. 061-05360) from an 1/100 dilution; Con A (Calbiochem 234567, $2.5 \mathrm{mg} / \mathrm{ml}$ ) from an $10 \mu \mathrm{g} / \mathrm{ml}$ and $40 \mu \mathrm{g} / \mathrm{ml}$ dilution. The mitogenic responses were measured by labelling the cultures with tritiated $\left({ }^{3} \mathrm{H}\right)$ thymidine. The LTT has been carried out according to the method described previously (Sabbe, de Bode and van Rood, 1983). In order to reduce the impact of the extreme high and low values the $\log _{10}$ of the counts per minute was computed and used for further analysis.

Culture medium. For all cell cultures the same tissue culture medium was used, namely RPMI 1640 supplemented with antibiotics ( $1 \% 00$ gentamycine), 3mM/1 L- glutamine and $15 \%$ heat-inactivated pooled human serum. By testing all blood samples of a given subject on the same day and in the same experiment with use of the same culture media throughout the study, the laboratory test variation was kept limited (Merker et al., 1979).

\section{Statistical analysis}

Data were statistically analyzed by means of the SPSS-X MANOVA-module for multivariate analysis of variance.

At first stage all variables were analyzed separately in a two-way factorial analysis of variance with factors subject (1-47) and time (I-XII). Although the design of the experiment with only 5 measurements per subject implies that the data matrix is far from complete, it is feasible to test for subject-effect and for time-effect and to obtain estimates of the subject-effect for all 47 subjects and of the time-effect for all 12 timeperiods by fitting an additive subject and time model. By definition, these estimates are adjusted for the lack of balance in the data matrix (Fleiss, 1986, chap. 5.4.).

At the second stage the obtained subject-effects (corrected for time-effect) and timeeffects (corrected for subject-effect) for all variables were stored in a subject-effect data matrix with 47 rows and as many columns as variables in the study and in a time-effect data matrix with 12 rows and as many columns as variables in the study, respectively. From this new data matrix Pearson correlations between variables were obtained at the subject level and at the time level.

Finally, Pearson correlations between variables at the change-within-subject level were obtained. In an analysis with only two data sampling moments this correlation for variables $Y$ and $X$ is equal to the correlation between the $Y$-changes and the $X$ changes of all subjects. In a design with more than two moments of data sampling, the correlation can be obtained by computing the residuals in the two-factor subject by time analysis and then correlating X-residuals with $\mathrm{Y}$-residuals. These correlations are produced automatically by SPSS-MANOVA ("print error(cor)") when performing a multivariate two-way factorial subject by time analysis of variance on the variables $\mathrm{Y}$ and $\mathrm{X}$ (Norusis, 1988, p. C73).

The correlations and corresponding $\mathrm{p}$-values are given without correction for multiple testing. In judging the significance of the obtained p-values there is the danger of multiple testing. However, some of the variables can be grouped into the following blocks: subjective distress (average, lowest and highest subjective distress), immunoglobuline concentrations (IgG and IgM concentrations), CML (test 1,2, and 3), 
MLC (test 1,2 and 3), and LTT (response to the different mitogens). Since the number of blocks is limited, we feel free to conclude that there is a significant correlation between two blocks variables if all of the correlations show a consistent pattern and if most of them are significant at the .05 -level.

\section{RESULTS}

Associations at the subject level

The between-subject-effects were highly significant for all the variables (data not shown, van Rood et al., 1991).

A significant negative correlation was observed on the subject level for the number of glasses of alcohol containing beverages consumed per day (data not shown) and the percentage of CD3, $(r=-0.33, p=0.012)$ and CD4 $(r=-0.28, p=0.029)$ cells and the response to the mitogen PHA $(r=-0.27, p=0.031)$. The observed association between the response to the mitogen PHA and the number of alcohol containing beverages consumed per day could quite well be a chance-observation since the observed correlations were not consistently significant within the block of mitogen responses. Contrary to the findings as presented by Holt (1987), not significant correlations were observed between the number of cigarettes smoked per day and any of the immunological variables.

The immunological and psychological mean values, corrected for changes over time, were calculated. Correlations between immunological and psychological variables are presented in Table 2. To save space variables that showed no significant correlations at all such as depressive reaction pattern are not included in the table.

A significant negative correlation was observed between active problem solving and number of eosinophiles and number of lymphocytes and a significant positive correlation with polynucleair neutrophiles and neutrophiles. Furthermore, use of the coping strategy expression of emotions was negatively correlated with the number of eosinophiles. The GHQ-score is negatively correlated with the percentage of monocytes and positively correlated with serum $\operatorname{IgM}$ concentration. This is in accordance with the observation of Vassend and Halvorsen (1987). The percentage of OKMI cells was positively correlated with average subjective distress and the percentage of leucocytes with lowest subjective distress. Furthermore, all the correlations between average subjective distress and highest subjective distress and the mitogen responses against PHA, PWM, ConA 10 and ConA 40 are in the same direction and, with exception of average subjective distress with PHA and highest subjective distress with ConA 10, significant. This indicates that subjects high on measures of subjective distress are low in their proliferative response to mitogens.

Summarizing, for all variables tested in this study significant subject-effects were observed. Furthermore, some of the psychological variables correlated significantly with immunological variables, at the subject level. The correlations between variables measuring subjective distress and the mitogen responses were consistent and significant.

\section{Time-effects}

Significant differences were observed between the mean of the values before the defense of the thesis, in period I to VI, and the mean of the values after defense of 
Table 2 Correlations between immunological and psychological variables at the subject level

\begin{tabular}{lccccccr}
\hline & ASD & HSD & LSD & SD & APS & \multicolumn{1}{c}{ EE } & GHQ \\
\hline LEUC & 0.20 & 0.15 & $0.29^{*}$ & -0.10 & 0.11 & 0.10 & 0.15 \\
EO & 0.16 & 0.13 & 0.11 & -0.06 & $-0.34^{*}$ & $-0.33^{*}$ & -0.05 \\
PNN & -0.04 & -0.12 & -0.04 & 0.12 & $0.43^{*}$ & 0.19 & 0.08 \\
NEUT & 0.01 & 0.05 & 0.04 & 0.20 & $0.38^{*}$ & 0.24 & 0.15 \\
LYMF & 0.04 & 0.03 & -0.01 & -0.16 & $-0.41^{*}$ & -0.11 & 0.02 \\
MON & -0.15 & -0.22 & -0.09 & 0.06 & 0.07 & -0.08 & $-0.61^{* *}$ \\
OKMI & $0.29^{*}$ & 0.25 & 0.09 & 0.19 & -0.15 & 0.12 & 0.19 \\
PHA & -0.22 & $-0.33^{*}$ & -0.06 & -0.16 & 0.08 & -0.08 & -0.11 \\
PWM & $-0.29^{*}$ & $-0.31^{*}$ & -0.02 & -0.06 & 0.20 & 0.06 & 0.08 \\
ConA10 & $-0.30^{*}$ & -0.28 & -0.22 & -0.02 & -0.10 & -0.05 & -0.21 \\
ConA40 & $-0.32^{*}$ & $-0.28^{*}$ & -0.21 & 0.00 & -0.03 & -0.00 & -0.17 \\
IgG & 0.24 & 0.23 & 0.10 & $0.29^{*}$ & -0.08 & 0.11 & 0.11 \\
IgM & $0.27^{*}$ & $0.45^{* *}$ & 0.19 & 0.18 & -0.12 & 0.01 & $0.28^{*}$ \\
\hline
\end{tabular}

$\mathrm{ASD}=$ average subjective distress, $\mathrm{HSD}=$ highest subjective distress, $\mathrm{LSD}=$ lowest subjective distress, $\mathrm{SD}=$ seeking distraction, $\mathrm{APS}=$ active problem solving, $\mathrm{EE}=$ expression of emotions, $\mathrm{GHQ}=$ general health questionnaire, Leuc $=$ leucocytes, $\mathrm{EO}=$ eosinophiles, $\mathrm{PNN}=$ polynucleair neutrophiles, NEUT $=$ neutrophiles, $\mathrm{LYM}=$ lymphocytes, $\mathrm{MON}=$ monocytes, $\mathrm{OKMI}=\mathrm{OKMI}$ positive cells, PHA = phytohaemagglutinin, $\mathrm{PWM}=$ pokeweed mitogen, ConAl0 = concanavalin $\mathrm{A} 10 \mu \mathrm{g} / \mathrm{ml}$ and $40 \mu \mathrm{g} / \mathrm{ml}, \mathrm{IgG}=$ immunoglobulin $\mathrm{G}, \operatorname{IgM}=$ immunoglobulin $\mathrm{M} . \mathrm{N}=47, * \mathrm{p} \leq 0.05, * * \mathrm{p} \leq 0.01$.

the thesis, in period VII to XII, for average subjective distress $(F=11.62, d f=1$, $p=0.001)$, highest subjective distress $(F=5.48, d f=1, p=0.021)$ and depressive reaction pattern $(F=20.38, d f=1, p=0.000)$. Thus, as expected, the defense of the thesis enhanced the variability in subjective distress, i.e. induced subjective distress. Furthermore, as anticipated, the period in which the subjects experienced the highest level of distress was in period IV ( 8 to 4 weeks before the defense of the thesis) as indicated by the higher values of average subjective distress, highest subjective distress and depressive reaction pattern. Four weeks after defense of the thesis, in period IX, the differences from the mean of the variables measuring distress became negative indicating that the subjects experienced less distress at that time.

The results of the questionnaire of recent life events (for those who defended their thesis in $1986(N=35))$ showed that there was no difference in reported stressful life events in the year before or after the defense of the thesis.

No significant time-effects were observed for the results of the General Health Questionnaire, the coping strategies seeking distraction, active problem solving and expression of emotion. Significant changes over time were observed for average subjective distress $(F=2.84, d f=11, p=0.002)$ and highest subjective distress $(F=4.17, d f=11, p=0.000)$ and for the coping strategy depressive reaction pattern $(F=2.93, d f=11, p=0.02)$ (Table 3).

As for the immunological data, no significant time-effects were found for the whole blood cell counts and differential cell counts, the MLC, the CML, the serum concentrations of $\operatorname{IgG}$ and IgM, nor for the mitogen response to PHA. However, a significant time-effect was observed for the percentage of CD4 cells $(F=1.96$, $d f=11, p=0.037)$ and for the proliferative response to PWM $(F=1.92, d f=11$, $p=0.040)$, ConA $10(F=2.38, d f=11, p=0.010)$ and ConA $40(F=2.56, d f=11$, $p=0.005)($ Table 3$)$.

The correlations between the differences from the mean for each period, for those variables for which a significant time-effect was observed, are shown in table 4 . The correlations between the immunological variables, percentage CD4 cells, and the 
Table 3 Global mean and deviations from the global mean per time-period for selected immunological and psychological variables

\begin{tabular}{lccccccc}
\hline Time & ASD & HSD & DRP & CD4 & PWM & ConA 10 & ConA 40 \\
\hline (mean & 44538 & 70187 & 19337 & 561378 & 44116 & 42512 & $46465)$ \\
I & -01389 & -05069 & 01568 & $-47278^{* *}$ & -00690 & -00441 & -00433 \\
II & 06538 & 01838 & 00869 & -15927 & -00486 & -00699 & -00436 \\
III & 06833 & 03001 & 02205 & -35877 & -00082 & -00103 & -00725 \\
IV & 09822 & $11110^{*}$ & $03895^{* *}$ & -11612 & -00023 & -00526 & -00506 \\
V & 01271 & 01011 & -00145 & 16233 & 00176 & 00508 & 00562 \\
VI & 06402 & $09653^{*}$ & 00880 & 03556 & 00070 & 00137 & -00164 \\
VII & 06544 & $12740^{*}$ & 00690 & 06933 & 00423 & 00066 & 00197 \\
VIII & 02507 & $09182^{*}$ & $-02220^{*}$ & -00663 & -00534 & -00350 & -00092 \\
IX & -06719 & $-12859^{* *}$ & -01206 & -10290 & -00398 & -00242 & -00077 \\
X & $-15732 * *$ & $-12355^{* *}$ & $-03228^{* *}$ & 07333 & -00435 & $-01136^{*}$ & -00622 \\
XI & -04642 & -01836 & $-02529^{*}$ & 26593 & $01191^{* *}$ & $01614^{* *}$ & $01481^{* * *}$ \\
XII & -11435 & $-16413^{* *}$ & -00778 & $60999^{* *}$ & 00790 & $01172^{* *}$ & 00816 \\
\hline
\end{tabular}

Dashed line between period VI and VII indicates moment of thesis defense, ASD=average subjective distress, $\mathrm{HSD}=$ highest subjective distress, $\mathrm{DRP}=$ depressive reaction pattern, $\mathrm{CD} 4=$ =percentage $\mathrm{CD} 4 \mathrm{cells}, \mathrm{PWM}=$ pokeweed mitogen, ConA $10=$ concanavalın A $10 \mu \mathrm{g} / \mathrm{ml}$ and $40 \mu \mathrm{g} / \mathrm{ml}{ }^{*} \mathrm{p} \leq 005,{ }^{*} \mathrm{p} \leq 001$

prolıferatıve response to PWM, and ConA, are all significant Withın the block of psychological variables, the correlation between highest subjective distress and depressive reaction pattern is not significant albeit in the same direction as the other significant correlations.

However, none of the correlations of interest, namely between psychological and immunological variables, reached the 0.05 level of significance (Table 4).

Summarizing, a significant time-effect was observed for some of the psychological (average subjective distress, highest subjective distress and depressive reaction pattern) and immunological measures (percentage CD4 cells, prohferative responses to PWM, ConA 10 and ConA40). However, none of the correlations between these psychological and immunological variables were significant, indicatıng a lack of congruency of the tume-effect patterns

Table 4 Correlatıons between selected immunological and psychological variables computed from the deviations from the global mean per time-period

\begin{tabular}{|c|c|c|c|c|c|c|c|}
\hline & $A S D$ & $H S D$ & $D R P$ & $C D 4$ & $P W M$ & ConA 10 & ConA40 \\
\hline \multicolumn{8}{|l|}{$\mathrm{ASD}$} \\
\hline HSD & $89 * *$ & & & & & & \\
\hline DRP & $75^{* *}$ & 49 & & & & & \\
\hline CD4 & -46 & -29 & -51 & & & & \\
\hline PWM & -13 & -02 & -17 & $75^{* * *}$ & & & \\
\hline ConA $: 0$ & -16 & -14 & -22 & $66^{*}$ & $89 * *$ & & \\
\hline $\operatorname{Con} A 40$ & -29 & -18 & -44 & $74 * *$ & $84 * *$ & $92^{* *}$ & \\
\hline
\end{tabular}

$\mathrm{ASD}=$ average subjective distress, $\mathrm{HSD}=$ highest subjective distress, $\mathrm{DRP}=$ depressive reaction pattern, $\mathrm{CD} 4$ - percentage CD4 cells, $\mathrm{PWM}=$ pokeweed mitogen, ConA10 = concanavalin $\mathrm{A} 10 \mu \mathrm{g} / \mathrm{ml}$ and $40 \mu \mathrm{g} / \mathrm{ml} \mathrm{N}=12$ periods $* \mathrm{p} \leq 005 * * \mathrm{p} \leq 001,2$-tailed significance 
Assoclations at the change-within-subject level

At the change-within-subject level some significant correlations were observed (Table 5)

The only correlations which were highly significant were within the block of variables measuring proliferative response to the mitogens and within the block of variables measuring subjective distress (Table 6).

Within the block of mitogen responses, the results at the time level and changewithin-subject level are significant and consistent. The same applies for the correlations within the block of subjective distress (Table 4 and Table 6) However, the absolute lack of cross-correlation between psychological and immunological variables for which a sıgnificant time-effect was observed should be noted (Table 6)

Tables 5 Correlations between selected immunological and psychological variables computed from the changes within subjects corrected for time period

\begin{tabular}{|c|c|c|c|c|c|c|c|c|}
\hline & $A S D$ & $H S D$ & $L S D$ & $S D$ & $A P S$ & $E E$ & $D R P$ & $G H Q$ \\
\hline HT & 005 & 006 & 006 & 016 & -002 & $020^{*}$ & 007 & 000 \\
\hline ERY & 010 & 005 & 011 & 013 & -007 & $022^{*}$ & 004 & 002 \\
\hline LEUC & 002 & -002 & 001 & -016 & $-026^{*}$ & -004 & -006 & 007 \\
\hline $\mathrm{CD} 3$ & -008 & 011 & -015 & 005 & -015 & -013 & -015 & $-019 *$ \\
\hline CD8 & 004 & -003 & 013 & -007 & -003 & -002 & -001 & $-019^{*}$ \\
\hline $\mathrm{CD} 4 / \mathrm{CD} 8$ & 003 & 011 & -000 & -006 & 008 & 007 & 005 & $020^{*}$ \\
\hline TAC & -011 & -012 & $-020^{*}$ & 013 & 007 & -017 & -010 & -011 \\
\hline CD16 & 007 & -004 & $-020^{*}$ & 004 & -001 & 002 & 010 & -002 \\
\hline ConA40 & 005 & 011 & -002 & 002 & -004 & 010 & 010 & $019^{*}$ \\
\hline
\end{tabular}

$\mathrm{ASD}=$ average subjective distress, $\mathrm{HSD}=$ highest subjective distress, LSD = lowest subjective distress $\mathrm{SD}=$ seeking distraction $\mathrm{APS}=$ active problem solving, $\mathrm{EE}=$ expression of emotions, $\mathrm{DPR}=$ depressive reaction pattern, GHQ = general health questionnare, HT = haematrocit volume, ERY=erytrocytes, $\mathrm{LEUC}=$ leucocytes, $\mathrm{CD} 3=$ percentage $\mathrm{CD} 3$ positive cells, $\mathrm{CD} 8=$ percentage $\mathrm{CD} 8$ positive cells, $\mathrm{CD} 4 / \mathrm{CD} 8=$ ratio between percentage CD4 and CD8 positive cells, TAC $=$ percentage cells with II-2 receptor, CD16 = percentage CD16 positive cells, ConA40 = concanavalın A $40 \mu \mathrm{g} / \mathrm{ml}$ Degrees of freedom of each correlation coefficient varies from $100-120, * \mathrm{p} \leq 005,2$ taled significance

Tables 6 Correlations between selected immunological and psychological variables computed from the changes within subjects corrected for time period

\begin{tabular}{|c|c|c|c|c|c|c|c|}
\hline & ASD & HSD & DRP & $\mathrm{CD} 4$ & PWM & ConA10 & ConA40 \\
\hline \multicolumn{8}{|l|}{$\mathrm{ASD}$} \\
\hline HSD & $71 * *$ & & & & & & \\
\hline DRP & $42^{* * *}$ & $48 * *$ & & & & & \\
\hline $\mathrm{CD} 4$ & 10 & 18 & 07 & & & & \\
\hline PWM & -01 & 08 & 04 & 35 & & & \\
\hline ConA 10 & 07 & 15 & 11 & 16 & $68^{* k}$ & & \\
\hline ConA40 & 01 & 10 & 06 & 18 & $76^{* * *}$ & $86^{*-k}$ & \\
\hline
\end{tabular}

$\mathrm{ASD}=$ average subjective distress, $\mathrm{HSD}=$ highest subjective distress, $\mathrm{DRP}=$ depressive reaction pattern, $\mathrm{CD} 4$ $=$ percentage CD4 positive cells, $\mathrm{PWM}=$ pokeweed mitogen, ConA10\&40 = concanavalın A $(10 \mu \mathrm{g} / \mathrm{ml}$ and 40 $\mu \mathrm{g} / \mathrm{ml}) \mathrm{N}=47,^{* * *}=\mathrm{p} \leq 001$ 
We conclude that for none of the psychological and immunological variables tested in this study a truly causal relation could be established although some of them showed some similarity at the time-level, resulting in moderate correlations (Table 4).

\section{DISCUSSION}

\section{Subject-level}

A significant subject effect was observed for all psychological and immunological variables studied. All those characteristics of subjects which remain constant over time within one subject and for which mutual subjects can differ, can enhance between subject variability in immunological test results. The between subject variability in this study accounted for about $70 \%$ of the total variance of the immunological variables even though the heterogeneity of the study group was reduced by the exclusion of those subjects who drank 4 or more glasses of alcohol a day or who had a chronic disease for which they used immune-modulating medication (Van Rood et al., 1991).

Although the between subject variability may be smaller in studies which use more stringent selection criteria we expect that even then a large proportion of the variability in immunological test results will be accounted for by the between subject variability. The relative dominance of the between subject variability implies that very large sample sizes are needed to find significant differences between groups if only a single observation is available. However, if the same group of subjects is repeatedly, and preferably more than twice, measured for the same immunological parameters then the between subject variability can easily be taken into account by use of repeated measures MANOVA as we did. Other sources of variation of interest to the investigator can hereafter be estimated with greater accuracy.

The correlations between psychological and immunological variables at the subject level were computed. Eighteen of the 91 correlations were significant. With so many comparisons there is the danger of multiple testing. However, in accordance with Vassend and Halvorsen (1987) a significant and positive correlation was observed between $\operatorname{IgM}$ concentrations and the sumscore on the General Health Questionnaire. Furthermore, within the block of mitogen responses all the correlations between average and highest subjective distress were in the same direction (negative) and 6 out of 8 were significant. It is quite surprising that the mitogen responses to PWM, PHA and ConA form such a consistent block, because of PWM requiring T and B cell coordination, whereas PHA and ConA are T cell mitogens. Finally, the correlations between the immunoglobulines $\operatorname{IgG}$ and $\operatorname{IgM}$ and average and highest subjective distress are in the same direction (positive). However, only the correlations between subjective distress and IgM were significant.

Associations at the subject level can well be independent of the association at the time and change-within-subject levels, because they represent long term subject levels which can be related to completely different biological mechanisms than those which change over time. 
Time level

A significant time effect was observed for average subjective distress, highest subjective distress, and use of the coping strategy depressive reaction pattern. As for the immunological variables, a significant time effect was observed for percentage CD4 cells, and the proliferative responses to PWM, ConA10 and ConA40.

None of the correlations, at the time level, between these psychological and immunological variables reached the 0.05 level of significance. However, the correlations between percentage of CD4 cells and average subjective distress $(r=$ $-0.46, \mathrm{p}<0.15)$ and depressive reaction pattern $(r=-0.51, p=0.13)$ were quite substantial, though not significant. This is an indication of a similar pattern over time and in line with the findings of Glaser et al. (1985a) and Kiecolt-Glaser et al. (1986) who observed a significant decline in percentage CD4 cells during a stress period and Halvorsen and Vassend (1987) and Naliboff et al. (1991) who observed a nonsignificant decline. On the other hand, Taylor, Neale and Dardano (1986) observed a non-significant rise, and Landman et al. (1984) no change in percentage of CD4 cells during a stress period.

Glaser et al. (1985a) observed significant lower mitogen responses to PHA and ConA during examination compared to baseline samples. Taylor et al. (1986) and Halvorsen and Vassend (1987) observed a, non-significant, decline in mitogen response to PHA during stress. The main difference between these studies and our study

that there the hypothesis was tested that examination samples differed from baseline samples, whereas we tested whether changes in subjective distress were associated with changes in immunological outcome measures. Glaser et al. (1990) also observed small and non-significant correlations between self-report measures and immunological values. They suggest that this is understandable since they used an acute stressor, small samples (study 1: 4 samples, $N=22$; study 2: 2 samples, $N=25$; study $3: 2$ samples, $N=44$ ) and relatively small ranges for the stress response (five point scale). As compared to the study of Glaser et al. (1990) we used a larger sample (5 samples, $N=47$ ), and had a larger range for the stress measure (ten point scale). However, we also did not observe a significant association between self-report measures and the immunological values. An explanation also brought forward by Glaser et al. (1990) is that the immunological changes which are measured occur over the course of several days to a week or more. The changes in immunological values would only become observable some time after exposure to the stressor, or the psychological response to the stressor. However, this is not in accordance with the work of those authors which observe significant differences between examination and baseline samples (Jemmott et al., 1983; Jemmott and McClelland, 1988; KiecoltGlaser et al., 1984a, 1984b, 1986; Glaser et al., 1985a, 1985b, 1986a, 1986b, 1987, 1990; McClelland et al., 1985; Vassend and Halvorsen, 1987; Mouton et al., 1989; Tomei et al., 1990). If, on the other hand, the observed changes are the result of anticipation stress, then it would be pure coincidence that changes in immunological values were already observable during the examination. To gain insight in these relations and the optimal timing, it is necessary to investigate the relations between self-report measures and immunological values, for different time intervals. 


\section{Change-within-subject level}

Significant correlations at the time level, are only of interest when they are supported by correlations at the change-within-subject level. In our study the correlations between the psychological and immunological variables at the change-within-subject level were absent. Hence, in this study, no causal relation between psychological and immunological variables could be established.

\section{Method}

In this study 47 subjects were measured 5 times, for both psychological and immunological variables. Only Kiecolt-Glaser et al., $N=61,2$ samples (1984a), Glaser et al., $N=49,3$ samples (1985b) and Fittschen et al., $N=61,3$ samples (1990) studied a larger number of subjects. However, in none of the studies so many samples were taken. The large number of samples allowed for a reliable estimation of the subject effect. Correction for the subject effect resulted in a substantial reduction of the standard error and more reliable estimation of the time effect (Van Rood et al., 1991).

The creation of post-hoc 12 time periods, resulted in an incomplete data set. As Table 1 shows, period $I$ is overrepresented but the remaining measurements are reasonably spread out over the other periods. The significant time effects for average subjective distress, highest subjective distress, depressive reaction pattern, percentage CD4 cells, the proliferative response to PWM, ConA 10 and ConA40, show that reasonable statistical power is obtained. The analysis of change between subjects is not very much affected by the lack of balance and has a good power due to the 5 measurements per individual. This can be observed from Table 5, where a correlation of 0.19 is already statistically significant.

\section{Psychological variables}

In psycho-immunological field studies, it is impossible to bring all life stressors under control of the investigator, let alone all factors which could influence the process by which subjects appraise, evaluate and interpret situations. Subjective stress is not only determined by the impact of the life event under study but also by the impact of other events and/or daily hassles, not under control of the investigator. The latter stress is often treated as error-variability. In our opinion it is impossible to determine what the impact of the life event under study is independent from the impact of other events, not under control of the investigator. Hence, the latter uncontrollable stress should not be treated as error-variability. By asking the subjects, as we did in our sturiy, to indicate the intensity of their subjective distress at the moment of assessment, the total impact of all life events and daily hassles, as experienced by the subjezt, is assessed. Since this measure had not been validated as yet, it is not clear how well it measures subjective distress. However, we did observe significant differences between pre and post defense scores, as predicted, which is suggestive for some external validity. Furthermore, a consistent and significant correlation was 
observed between the scores of average and highest subjective distress at both the time and change-within-subject level, which is suggestive for some internal validity.

The stresssor used in our study, the defense of a PhD thesis, could have been too low in intensity to induce enough between sample variability to observe a significant association between subjective distress and immunological variables at the changewithin-subject level. However, the event was intense enough to induce significant changes in subjective distress over time in relation to the event. A more likely explanation of our negative findings is that by the choice of data sampling moments, i.e. before and after defense of the thesis but not on the day itself, the stress induced between sample variability was reduced.

A short version of the Utrechtse Coping List was used, to increase the participation rate of the subjects. The combination of venapuncture, and filling in questionnaires, was so unpleasant that it was decided to make the questionnaires as short as possible. It was not expected that the use of coping strategies would change over time. The significant time effect for depressive reaction pattern, suggests that the use of the coping strategy depressive reaction pattern is situation dependent, and is used more often when a subject is distressed or that distress increases because the subject makes more use of this (cognitive) coping strategy.

\section{Immunological variables}

To limit laboratory test variation all samples from one individual were tested on the same day and in the same experiment. Therefore, blood lymphocytes were kept frozen in liquid nitrogen until all blood samples were collected. Separating, freezing and thawing of cells could make them less responsive to mitogenic stimulation. However, is so then it would be expected, contrary to our observations, that no significant correlations at the change-within-subject level between the mitogenic responses would be observed. Furthermore, Merker et al. (1979) investigated the effect of cryopreservation on the resuslts of lymphocyte stimulation assays with the mitogens ConA, PHA and PWM. They conclude that: "the cell suspensions consist of mononuclear cells, predominantly small lymphocytes, whose properties in (...) mitogen stimulation assays, even after freezing and thawing, are comparable to those of gradient-separated peripheral blood cells" (p.124).

We observed no significant time-effect for whole blood cell count, differential cell counts, the results of mixed lymphocyte culture and the cell mediated lympholysis. This indicates that these immunological variables are not suited for use in psychoimmunological studies in which the between sample variability is of main interest as in longitudinal and quasi-experimental studies.

Our study showed the value of repeated data collection from individuals subject to natural stressful events. In observational or quasi-experimental studies as the kind we performed, changes within a subject can reveal important information about the effect of stressors on immunological and psychological variables. Although we were not able to find significant associations between changes in immunological and psychological variables, we do think that the methodology we presented can be useful in future studies provided larger differences within individuals are observed. This asks for a stressor of sufficient intentsity and good timing of the moments of observation. 


\section{Author notes}

This project has been subsidised by the MACROPA foundation. We thank F Konıng, $\mathrm{PhD}$, for his advise and support.

\section{References}

Ader, R (Ed) (1981) Psychoneuroummunology New York Academıc Press

Ader, R, Felten, D L and Cohen, N (Eds) (1991) Psychöneuloummunology (2nd ed) New York Academic Press

Crowder, M J and Hand, D J (1990) Analysıs of repeated measures Monographs on stattstics and applied probabiltty 41 London Chapman and Hall

Dorian, B, Garfinkel, P, Brown, G, Shore, A, Gladman D and Keystone, E (1982) Aberrations in lymphocyte subpopulations and function during psychological stress Clinical Experimental Immunology, 50, 132-138

Fittschen, B, Schulz, K-H, Schulz, H, Raedler, A and Kerekjarto van, M (1990) Changes of immunological parameters in healthy subjects under examination stress Inteinational Jounal of Neurosclence, 51, 241-242

Fleiss, J L (1986) The desrgn and analysts of clmical expertments New York John Wiley and Sons

Glaser, R, Kiecolt-Glaser, J K, Stout, J C, Tarr, K L, Speicher, C E and Holliday, JE (1985a) Stress, related imparments in cellular immunity Psychtatry Reseaich, 16, 233-239

Glaser, R, Kiecolt-Glaser, J K, Speicher, C E and Hollıday, J E (1985b) Stress, lonelıness, and changes in herpes virus latency Joum nal of Behavioral Medicine, 8, 249-260

Glaser, R, Rice, J, Speıcher, C E, Stout, J C and Kiecolt-Glaser, J K (1986a) Stress depresses interferon production by leukocytes concomitant with a decrease in natural killer cell activity Behavioral Neuloscience, 100(5), 675-678

Glaser, R , Mehl, V S , Penn, G, Speicher, C E and Kiecolt-Glaser, J K (1986b) Stress-associated changes in plasma immunoglobulin levels International Journal of Psychosomatics, 33(2), 41-42

Glaser, R, Rice, J , Sherıdan, J, Fertel, R, Stout, J, Speıcher, C, Pinsky, D, Kotur, M, Post, A , Beck, $M$ and Kiecolt-Glaser, J (1987) Stress-related immune suppression health implications Brain Behaviou and Immuntty, 1, 7-20

Glaser, R , Kennedy, S , Lafuse, P , Bonneau, R H , Spercher, C Hillhouse, J and Kiecolt-Glaser, J K (1990) Psychological stress induced modulation of interleukın 2 receptor gene expression and interleukin 2 production in peripheral blood leukocytes Aichives of General Psychiatry, 47, 707-712

Goldberg, D P and Hillier, V F (1979) Scaled version of the General Health Questionnarre Psychological Medicine 9(1), 139-145

Goulmy, E (1982) HLA A, -B restriction of cytotoxic T Cells In S Ferrone and B G Solherm (Eds ), HLAtyptng methodology and clinical relevance (pp 105-122) West Palm Beach CRC press

Halvorsen, $R$ and Vassend, $O$ (1987) Effects of examnation stress on some cellular immunity functions Jounal of Psychosomatic Research, 31(6), 693-701

Hartzmann, RJ, Segall, M, Bach, ML and Bach, FH (1971) Histocompatibility matching VI Mintaturization of the mixed leukocyte culture test a preliminary report Tiansplantation 11, 268-273

Holt, P G (1987) Immune and inflammatory function in crgarette smokers Thor ax, 42, 24l-249

Jemmott, J B , Borysenko, M, Chapman, R, Borysenko, JZ, McClelland, D C, Meyer, D and Benson, $H$ (1983) Academic stress, power motivation, and decrease in secretion rate of salivary secretory immunoglobulin A The Lancet 8339(1), 1400-1402

Jemmott, J B and McClelland, D C (1988) Academic stress, soctal support, and secretory ummunoglobuln A Joun nal of Per sonality and Social Psychology 55(5), 803-810

Kiecolt Glaser, J K, Garner, W, Spercher, C, Penn, G M, Holliday, J E and Glaser, R (1984a) Psychological moditiers of immunocompetence in medical students Psychosomattc Medicme, 46, 7-14

Kiecolt Glaser, J K, Speicher, C, Hollıday, J E and Glaser, R (1984b) Stress and the transformation of lymphocytes by Epstem Barr virus Joum nal of Behavioral Medicine, 7(1), 1-12

Kıecolt-Glaser, J K, Glaser, R , Strain, E C , Stout, J C, Tarr, K L , Hollıday, J E and Speıcher, C E (1986) Modulation of cellular immunity in medical students Journal of Behavioral Medicine 9 5-21

Landmann, R M A, Muller F B, Perın, Ch, Wesp, M, Erne, P and Buhler, F R, (1984) Changes of immunoregulatory cells induced by psychological and physical stress relationship to plasma catecholam nes Clinical Experimental Immunology 58, 127-135

MacGregor, R R (1986) Alcohol and immune defense Joumal of the Amertcan Medical Association, 256(11), 1474-1479 
McClelland, D C, Ross, G and Patel, V (1985) The effect of dcademic examination on salıvary norepinephrine and immunoglobuln levels Journal of Human Stess, 11(2), 52-59

Merker, R, Check, I and Hunter, R L (1979) Use of cryopreserved cells in quality control of human lymphocyte assays analysis of variation and limits of reproducibility in long-term replicate studies Clinical Experimental Immunology, 38, 116-126

Mouton, C, Fillion, L, Tawadros, E and Tessier, R (1989) Salıvary IgA is a weak stress marker Behavioural Medicine, 15(4), 179-185

Nalıboff, B D, Benton, D, Solomon, G F, Morley, J E, Fahey, J L, Bloom, E T, Makınodan, T and Gilmore, S L (1991) Immunological changes in young and old adults during brief laboratory stress Psychosomatic Medicine, 53, 121-132.

Norusis, M J (1988) SPSS / PC+ Advanced Statistics V2 O Chicago SPSS WC

Rood van, Y, Goulmy, E, Blokland, E, Pool, J, Van Rood, J and Van Houwelingen, H (1991) Monthrelated variability in immunological test results, implications for immunological follow up studies Clinical Experimental Immunology, 86, 349-354

Rood van, Y R, Bogaards, M, Goulmy, E and van Houwelingen, H C (1993) The effects of stress and relaxation on the in vitro immune response in man a meta-analytic study Journal of Behavioral Medicine, 16, 613-181

Sabbe, L J M, de Bode, L and van Rood, J J (1983) Analysis of variability in lymphocyte transformation tests Journal of Immunological Methods, 57, 21-32

Salden, H J M , Bos, B M, Hermans, J T H and Janson, P C W (1988) Analytical performance of three commercially avalable nephelometers compared for quantıfyıng proteins in serum and cerebrospinal fludd Clinical Chemistry, 34, 1594-1596

Schreurs, J P G, van de Willige, G, Tellegen, B and Brosschot, J F (1988) De Utrechtse Copung Lijst UCL Manual, Lisse, Swets en Zeitlinger

Sternberg, J C (1977) A rate nephelometer for measuring specific proteins by immunoprecipitin reactions Clinical Chemistry, 23, 1456-1464

Taylor, GR, Neale, LS and Dardano, J R (1986) Immunological analyses of U S space shuttle crewmembers Aviation, Space and Envilonmental Medictne, 57(3), 213-217

Tomeı, L D , Kıecolt-Glaser, J K, Kennedy, S and Glaser, R (1990) Psychological stress and phorbol ester inhibition or radiation-induced apoptosis in human peripheral blood leukocytes Psychiatry Reseaich, 33, $59-71$

Vaisman, N , Hahn, T, Dayan, Y and Schattner, A (1990) The effect of different nutritional states on cell mediated cytotoxicity Immunology Letters, 24, 37-42

Vassend, $O$ and Halvorsen, $R$ (1987) Personality, examination stress and serum concentrations of immunoglobulins Scandinavian Journal of Psychology, 28, 233-241

Workman, E A and La V1a, M F (1987) T-lymphocytes polyclonal proliferation effects of stress and stress response style on medical students taking national board examinations Clinical Immunology and Immunopathology 43, 308-313

Willige van de, G, Schreurs, P, Tellegen, B and Zwart, F (1985) Het meten van 'life events' de Vragenlisst Recent Meegemaakte Gebeurtenissen (VRMG) (Measuring 'life events' Questionnare for recent life events) Nederlands Tijdschrift voor de Psychologie 40, 1-19 